Chirurg $2021 \cdot 92: 1050$

https://doi.org/10.1007/s00104-021-01526-2

Online publiziert: 7. Oktober 2021

(๑) Der/die Autor(en) 2021

\section{Erratum zu: Evaluation einer Therapieanpassung bei ASS-Low- Response in der Gefäßchirurgie}

T Hummel $^{1} \cdot$ S. H. Meves ${ }^{2} \cdot$ A. Breuer-Kaiser ${ }^{3}$ • J. O. Düsterwald ${ }^{1} \cdot$ D. Mühlberger ${ }^{1}$. A. Mumme ${ }^{1} \cdot$ H. Neubauer ${ }^{4}$

'Klinik für Gefäßchirurgie, St. Josef Hospital, Ruhr-Universität Bochum, Bochum, Deutschland

${ }^{2}$ Klinik für Neurologie, St. Josef Hospital, Ruhr-Universität Bochum, Bochum, Deutschland

${ }^{3}$ Klinik für Anästhesiologie und Intensivmedizin, St. Josef Hospital, Ruhr-Universität Bochum, Bochum, Deutschland

${ }^{4}$ Klinik für Kardiologie, St. Josef Hospital, Ruhr-Universität Bochum, Bochum, Deutschland
Die Online-Version des Originalartikels ist unter https://doi.org/10.1007/s00104-020-01280-x zu finden.

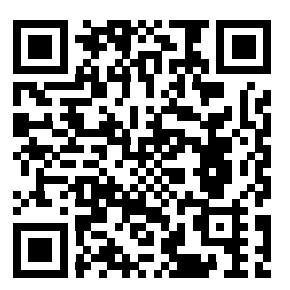

QR-Code scannen \&Beitrag online lesen

\section{Erratum zu:}

Chirurg 2020

https://doi.org/10.1007/s00104-020-

01280-x

Der Artikel „Evaluation einer Therapieanpassung bei ASS-Low-Response in der Gefäßchirurgie" von T. Hummel, S. H. Meves, A. Breuer-Kaiser, J. O. Düsterwald, D. Mühlberger, A. Mumme und $\mathrm{H}$. Neubauer wurde ursprünglich Online First ohne "Open Access" auf der Internetplattform des Verlags publiziert. Nach der Veröffentlichung in Band 92 Heft 7 pp. 640-646 hatten sich die Autoren für eine "Open Access"-Veröffentlichung entschieden. Das Urheberrecht des Artikels wurde deshalb in (c) Der/die Autor(en) 2020 geändert. Dieser Artikel ist jetzt unter der Creative Commons Namensnennung 4.0 International Lizenz veröffentlicht, welche die Nutzung, Vervielfältigung, Bearbeitung, Verbreitung und Wiedergabe in jeglichem Medium und Format erlaubt, sofern Sie den/die ursprünglichen Autor(en) und die Quelle ordnungsgemäß nennen, einen Link zur Creative Commons Lizenz beifügen und angeben, ob Änderungen vorgenommen wurden.

Die in diesem Artikel enthaltenen Bilder und sonstiges Drittmaterial unterliegen ebenfalls der genannten Creative Commons Lizenz, sofern sich aus der Abbildungslegende nichts anderes ergibt. Sofern das betreffende Material nicht unter der genannten Creative Commons Lizenz steht und die betreffende Handlung nicht nach gesetzlichen Vorschriften erlaubt ist, ist für die oben aufgeführten Weiterverwendungen des Materials die Einwilligung des jeweiligen Rechteinhabers einzuholen.

Weitere Details zur Lizenz entnehmen Sie bitte der Lizenzinformation auf http://creativecommons.org/licenses/by/ 4.0/deed.de.

Der Originalbeitrag wurde korrigiert.

\section{Korrespondenzadresse}

\section{Dr. T Hummel}

Klinik für Gefäßchirurgie, St. Josef Hospital, Ruhr-Universität Bochum

Gudrunstraße 56, 44791 Bochum, Deutschland thomas.hummel@rub.de

Open Access. Dieser Artikel wird unter der Creative Commons Namensnennung 4.0 International Lizenz veröffentlicht, welche die Nutzung, Vervielfältigung, Bearbeitung, Verbreitung und Wiedergabe in jeglichem Medium und Format erlaubt, sofern Sie den/die ursprünglichen Autor(en) und die Quelle ordnungsgemäß nennen, einen Link zur Creative Commons Lizenz beifügen und angeben, ob Änderungen vorgenommen wurden.

Die in diesem Artikel enthaltenen Bilder und sonstiges Drittmaterial unterliegen ebenfalls der genannten Creative Commons Lizenz, sofern sich aus der Abbildungslegende nichts anderes ergibt. Sofern das betreffende Material nicht unter der genannten Creative Commons Lizenz steht und die betreffende Handlung nicht nach gesetzlichen Vorschriften erlaubt ist, ist für die oben aufgeführten Weiterverwendungen des $\mathrm{Ma}$ terials die Einwilligung des jeweiligen Rechteinhabers einzuholen.

Weitere Details zur Lizenz entnehmen Sie bitte der Lizenzinformation auf http://creativecommons.org/ licenses/by/4.0/deed.de. 